\title{
Microvascular Changes During the Development of Follicles in Bovine Ovaries: A Study of Corrosion Casts by Scanning Electron Microscopy
}

\author{
Osamu Yamada ${ }^{1}$, Mitsuo Abe ${ }^{1}$, Kazushige Takehana ${ }^{1}$, Takeo Hiraga ${ }^{2}$, Kenji IwaSa ${ }^{1}$ and \\ Takahiro HIRATSUKA ${ }^{1}$ \\ Departments of Veterinary Anatomy ${ }^{1}$ and Veterinary Toxicology ${ }^{2}$, Rakuno Gakuen University, Ebetsu, Japan
}

Received February 1, 1995

\begin{abstract}
Summary. Microvascular changes during the development of follicles in bovine ovaries were studied by scanning electron microscopy of corrosion casts. A clear vascular plexus of ovarian follicles appeared at the stage when secondary follicles were $200-400 \mu \mathrm{m}$ in diameter. The plexus consisted initially of a thin, roughly structured and single-layered capillary network.

During follicular development, the microvascular architecture of antral follicles was arranged as two independent vascular plexuses. The inner plexus, which received a spiral arteriole, consisted of a dense sinusoidal capillary network with an arterial and a venous layer; it functioned as an independent microcirculatory unit. The inner plexus developed from the capillary plexus of the theca interna of the secondary follicles. The outer plexus, which anastomosed with several stromal capillaries, consisted of a thin, coarse and basket-like capillary plexus. The outer plexus was formed from the stromal capillary plexus as a consequence of the rapid enlargement of developing antral follicles.
\end{abstract}

During follicular development, the differentiation of the thecae folliculi is associated with the formation of the microvasculature (HAFEZ, 1987). In several mammals, this microvasculature is composed of a rough, single-layered capillary network. It appears in primary follicles, small secondary follicles or preantral follicles and then develops continuously during follicular development (ANDERSEN, 1926; KARDON and KESSEL, 1979; KANZAKI et al., 1982, MURAKAMI et al., 1988; KIKUTA et al., 1991; FORSMAN and MCCORMACK, 1992; MACCHIARELLI et al., 1992, 1993).

Several investigators have indicated that the microvasculature of bovine antral follicles consists of a basket-like sinusoidal capillary plexus (REUBER and EMMERSON, 1959; LAMOND and DROST, 1974; KÖNIG et al., 1989). However, no previous studies have demon- strated the changes in the microvascular pattern that occur with follicular development.

We provide here details of the appearance and transformation of the microvascular architecture during follicular development in bovine ovaries.

\section{MATERIALS AND METHODS}

Fifteen ovaries, removed from fifteen Holstein cows in the follicular phase, were used for a study by scanning electron microscopy (SEM) of corrosion casts. The follicles at various stages of development, as observed by SEM, were classified as primordial, primary, secondary and antral follicles by the method of MACCHIARELLI et al. (1992) and according to the classification by MARION et al. (1968).

The fifteen ovaries were perfused with physiological saline and then with a casting medium (Mercox 2B; Ohken Shoji, Tokyo) through the ovarian artery. They were placed in a hot water bath $\left(60^{\circ} \mathrm{C}\right)$, corroded in a hot solution of $10 \% \mathrm{NaOH}$ in water and washed overnight in running tap water. The blood vascular casts of the ovaries were frozen, sectioned, microdissected, air-dried, coated with gold in a vacuum evaporator (MURAKAMI et al., 1988) and analyzed by SEM (JSM-5200; JEOL, Tokyo) at an accelerating voltage of $10 \mathrm{kV}$.

\section{RESULTS}

The primordial and primary follicles, measuring less than $80-100 \mu \mathrm{m}$ in diameter, had no obvious vascular network. The secondary follicles of $100-200 \mu \mathrm{m}$ in diameter were surrounded by a polygonal meshwork 


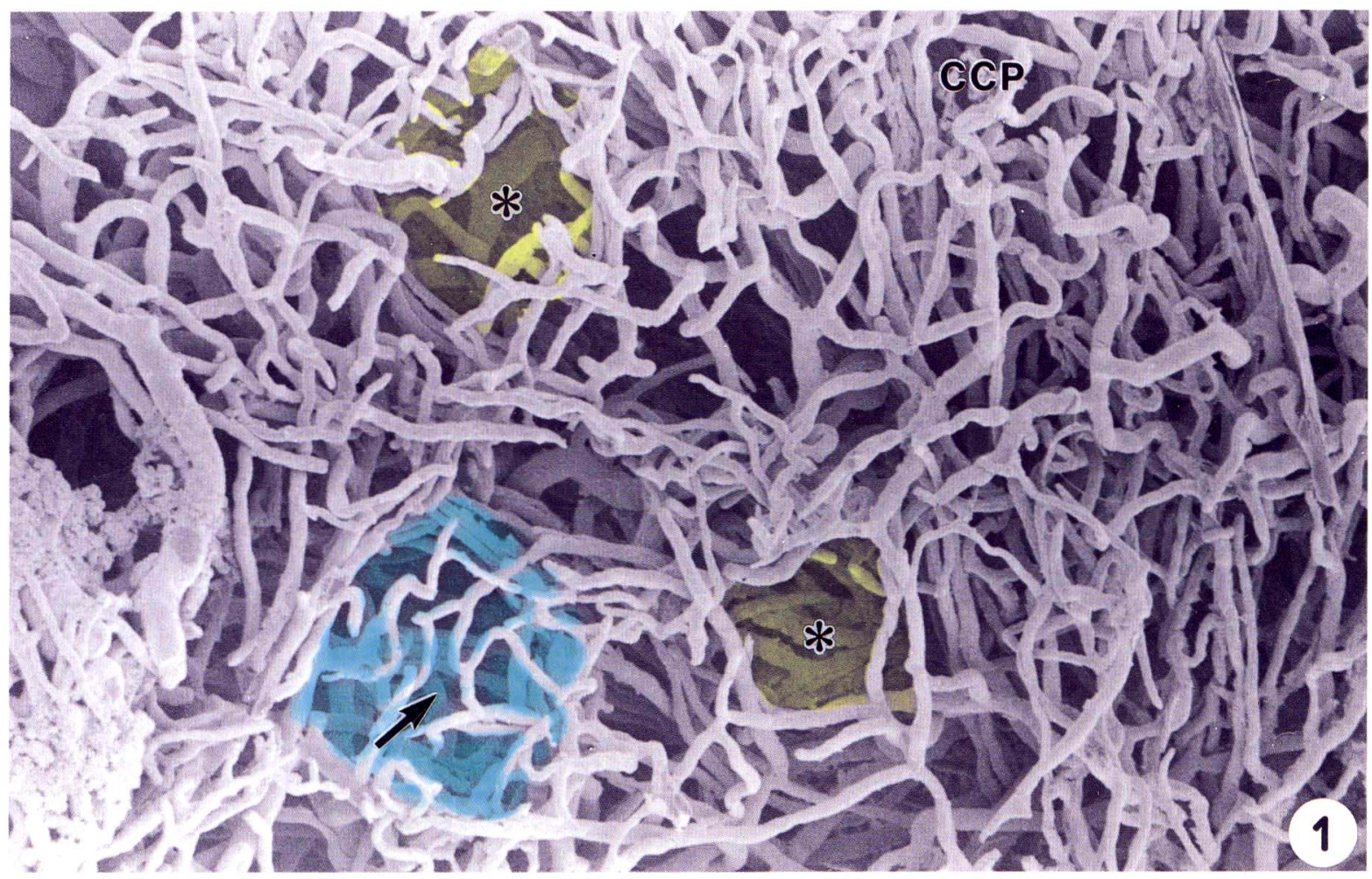

Fig. 1. Scanning electron micrograph of a vascular cast of primordial or primary follicles (asterisks) and of a secondary follicle of about $150 \mu \mathrm{m}$ in diameter (arrow). CCP cortical capillary plexus. $\times 120$

of a few large capillaries meshes, but no basket-like structure was visible (Fig. 1).

Developing secondary follicles of $200-400 \mu \mathrm{m}$ in diameter were supplied with an obvious, spherical microvascular network. The network was arranged as a thin, single layer of capillaries that anastomosed with a small arteriole displaying a slightly tortuous course and some cortical capillaries (Fig. 2). Copious coarse and polygonal networks of capillaries were organized just beneath the stratum granulosum. The capillaries extended into numerous thorn and sticklike projections.

On forming the follicular antrum, the follicles then grew to more than $400 \mu \mathrm{m}$ in diameter. Their microvascular architecture was composed of an inner dense, single-layered vascular plexus of $40-60 \mu \mathrm{m}$ in thickness, and an outer, coarse capillary plexus (Fig. $3)$. The inner plexus consisted of a small, spherical, basket-like capillary network that was surrounded by a layer of small arterioles and venules with an afferent arteriole with a tortuous course (Fig. 4). The afferent arteriole extended a few small arterioles that ran along the surface of the network from the basal part of the follicles; the arterioles branched into numerous capillaries of $10-20 \mu \mathrm{m}$ in diameter.
Extending into thorn-like projections and having some small holes, the capillaries were arranged as dense, oval or polygonal meshworks. They developed just below the stratum granulosum. Most of the capillaries drained away several small venules that enveloped the network, but some of the inner capillaries anastomosed with outer capillaries or stromal capillaries. The outer capillaries formed a rough network, similar to the stromal capillary network.

With a diameter of more than $1.0 \mathrm{~mm}$, the microvasculature of the antral follicles was arranged as an inner vascular plexus of about $100 \mu \mathrm{m}$ in thickness and an outer capillary plexus (Fig. 5). As the capillaries of the outer plexus completely lacked any connections with the capillaries of the inner plexus, both plexuses could easily be separated from each other (Fig. 6A, B).

The inner plexus, which had a spiral afferent arteriole, was divided into a large, spherical, dense sinusoidal capillary network and an arterial and venous layer (Figs. 5, 6A, 7). The spiral arteriole extended a few small arterioles that ran along the surface of the network from the basal part of the follice. Several branching arterioles merged with the sinusoidal capillaries of the inner plexus. The sinusoidal capillaries, 


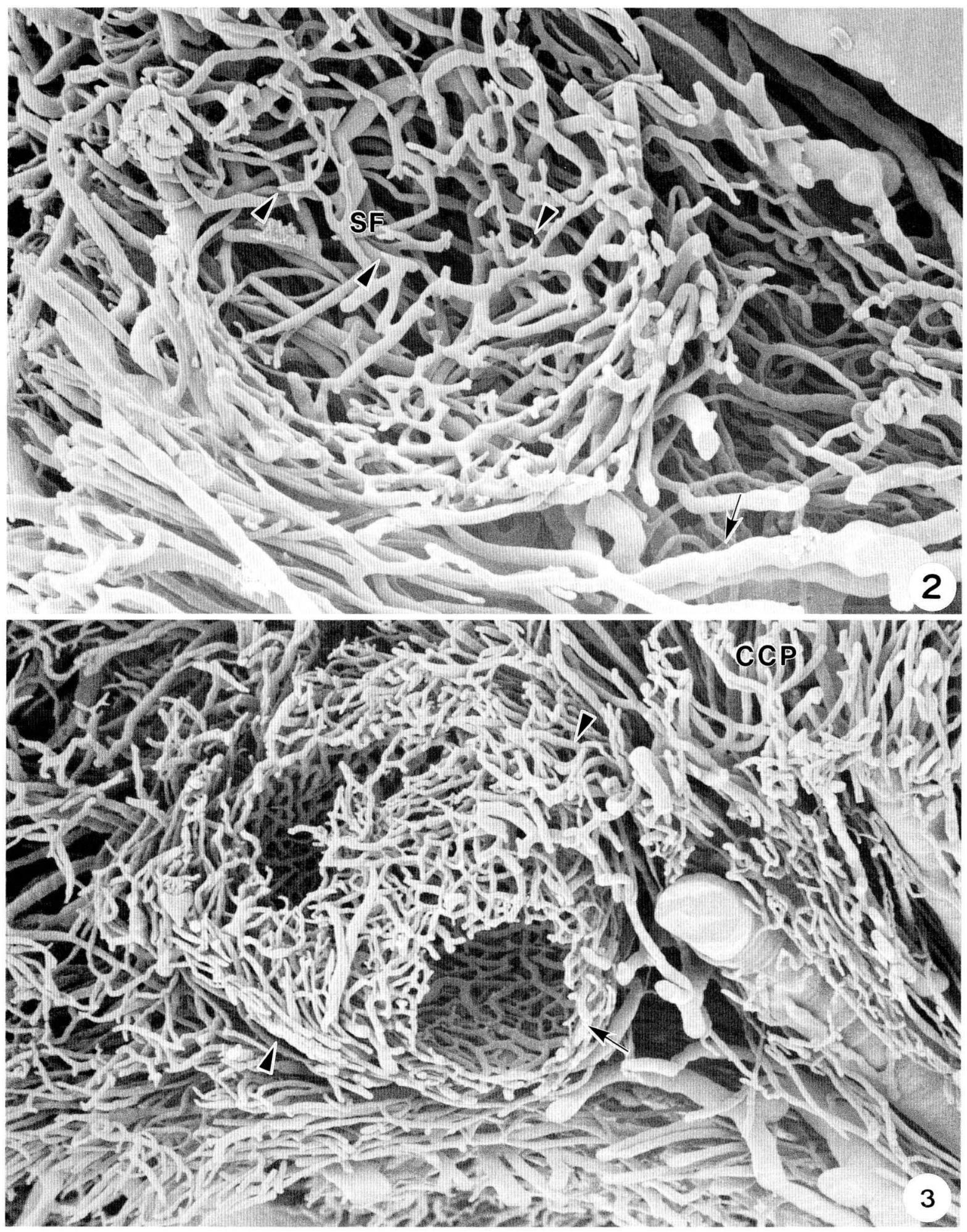

Fig. 2. Freeze-fractured vascular cast of a secondary follicle (SF) of about $400 \mu \mathrm{m}$ in diameter. The microvasculature comprises a single-layered capillary network. Arrowheads presumed sites of angiogenesis associated with vascular growth, arrow afferent arteriole. $\times 150$

Fig. 3. Freeze-fractured vascular cast of an antral follicle of about $600 \mu \mathrm{m}$ in diameter. The inner vascular plexus consists of a spherical, basket-like capillary network (arrow). The outer capillary plexus is located on the inner plexus (arrowheads). CCP cortical capillary plexus. $\times 80$ 


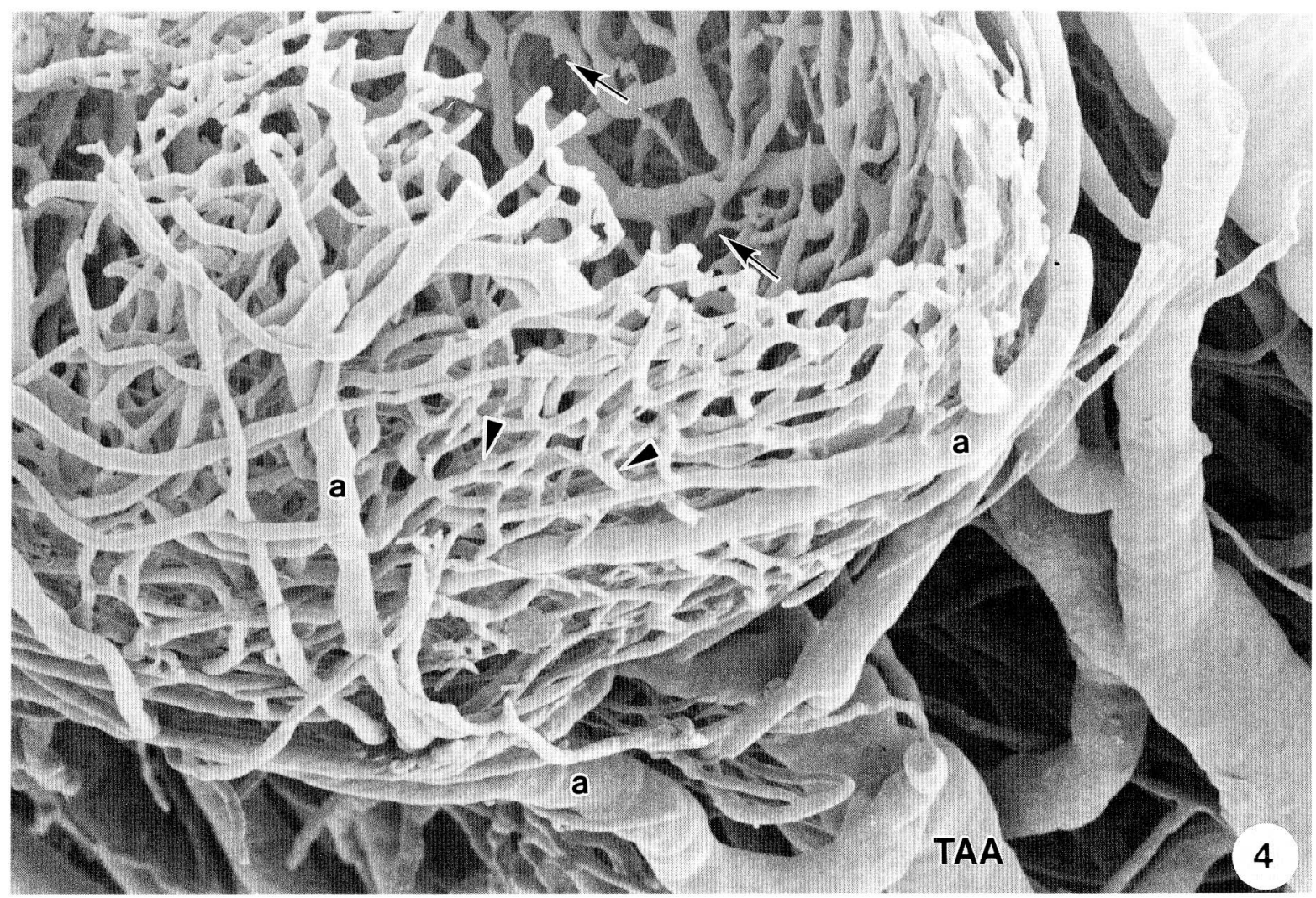

Fig. 4. Microdissected vascular cast of the inner vascular plexus of an antral follicle of about $600 \mu \mathrm{m}$ in diameter. An afferent arteriole taking a tortuous course (TAA) divides into a few small arterioles (a) that branch off from the capillaries of the inner vascular plexus (arrowheads). Arrow: angiogenesis. $\times 150$

which were $15-20 \mu \mathrm{m}$ in diameter, had some narrow holes and a few thorn-like projections; they formed a copious oval or polygonal meshwork (Fig. 8). All of the sinusoidal capillaries drained into several venules that enveloped the sinusoidal capillary network. The outer plexus was arranged as a rather coarse, basketlike network. Its mesh was larger than that of the stromal capillaries, and its capillaries were divided into cortical arterioles and stromal capillaries (Figs. $6 \mathrm{~B}, 7)$.

\section{DISCUSSION}

The microvascular changes during the development of ovarian follicles have been studied in several mammalian species (ANDERSEN, 1926; KARDON and KESSEL, 1979; KANZAKI et al., 1982; MuRAKAMI et al., 1988; KIKUTA et al., 1991; FORSMAN and MCCORMACK, 1993; MACCHIARELLI et al., 1992, 1993).

In the hamster, a vascular plexus can already be recognized in small primordial follicles (FORSMAN and MCCORMACK, 1993). In the rat, the primordial follicles lack a proper vascular plexus which appears at the stage when primary follicles are apparent. The plexus is organized into a single and sparse calillary wreath (MurakAmI et al., 1988; KIKUTA et al., 1991). During follicular development, it develops into a dense and single-layered configuration to yield an independent microcirculatory route with one or two afferent vessels (MURAKAMI et al., 1988; KikUTA et al., 1991). In the rabbit, a special follicular vascular

Fig. 5. Freeze-fractured vascular cast of an antral follicle of about $5.0 \mathrm{~mm}$ in diameter $(A F)$. The microvasculature consists of an inner $(I)$ and an outer $(O)$ vascular plexus. CCP cortical capillary plexus. $\times 20$

Fig. 6. Microdissected vascular casts of an antral follicle. A. The outside of the inner vascular plexus between the inner and outer vascular plexus. Small arterioles $(a)$ and venules $(v)$ run along the surface of the sinusoidal capillary network. B. The outer capillary plexus separates the inner vascular plexus from the two capillary plexuses. Several disorganized capillary networkes are visible (asterisks). A, B: $\times 45$ 


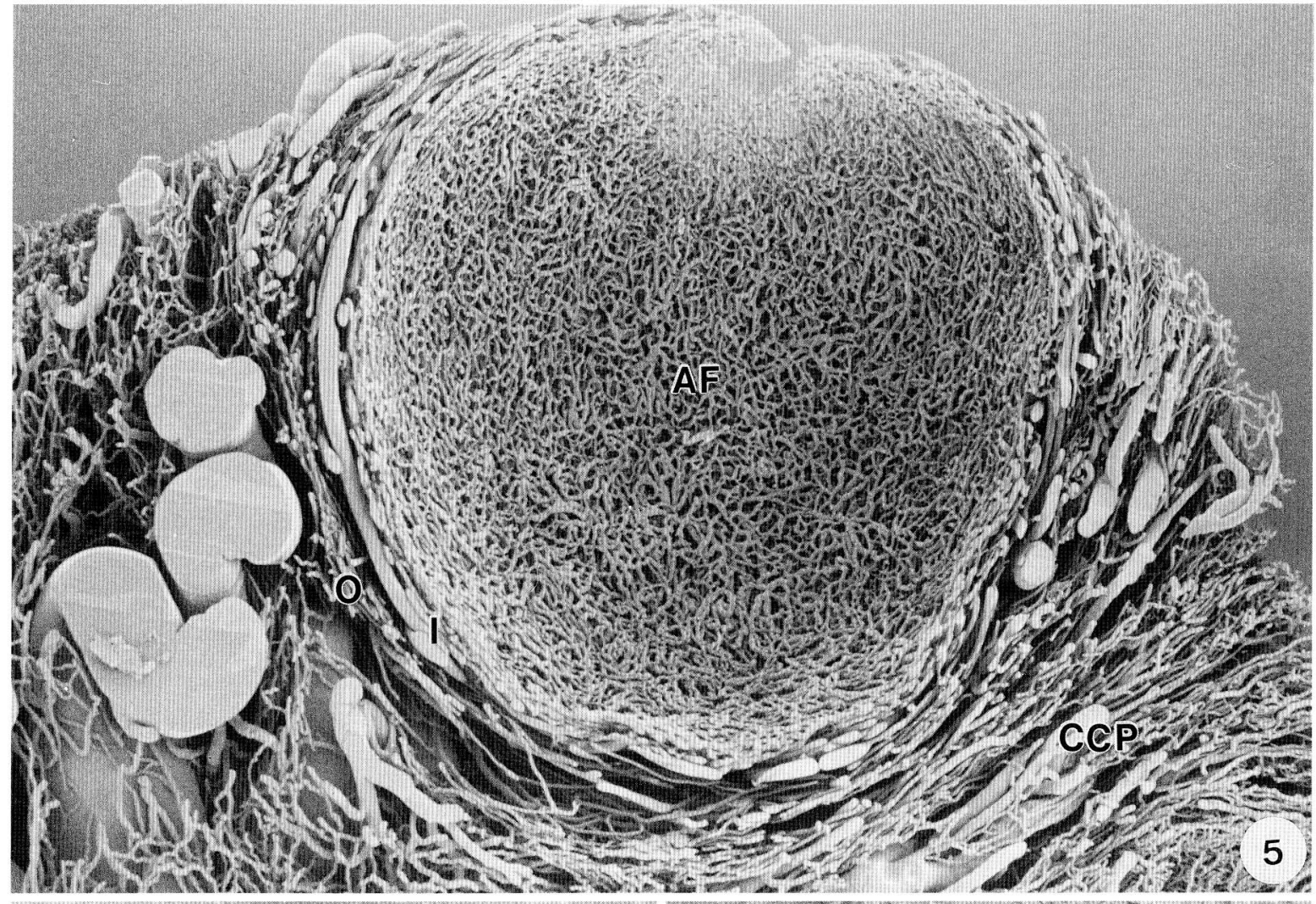

Nox jos wo.

4,1 :

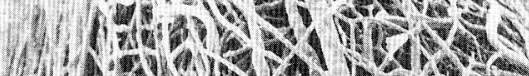

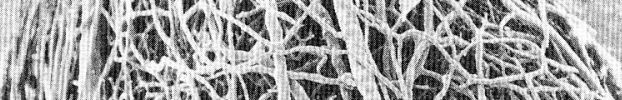

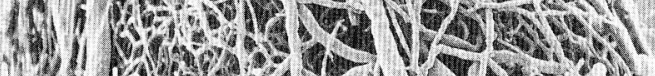

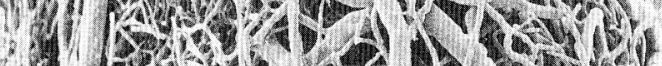
7.

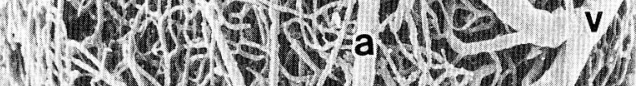

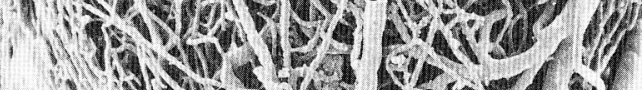

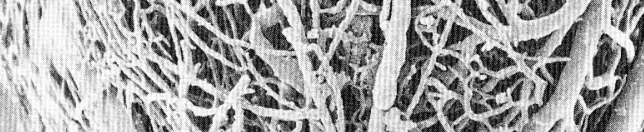

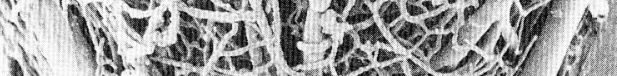

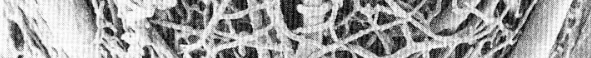

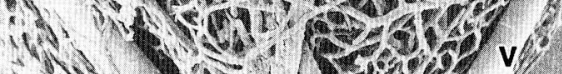

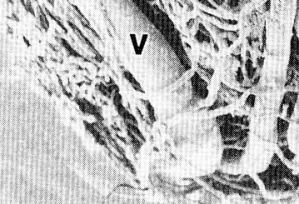

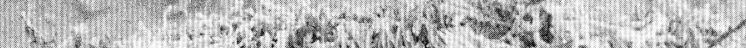

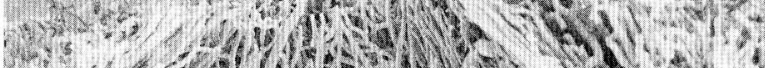
M 4 -

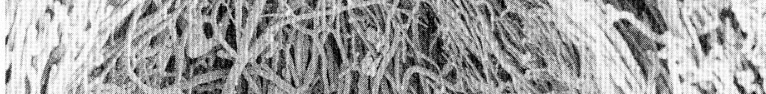

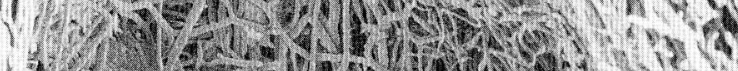

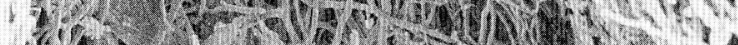

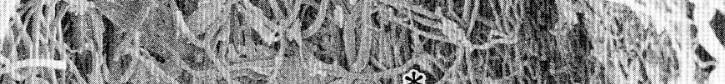

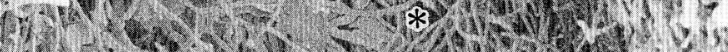

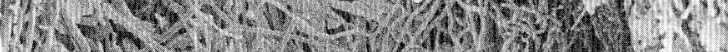
H.

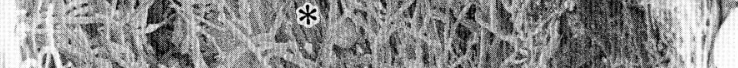

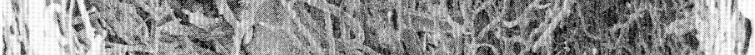

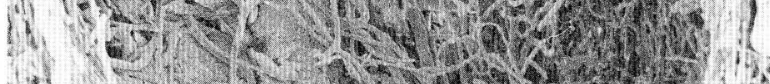

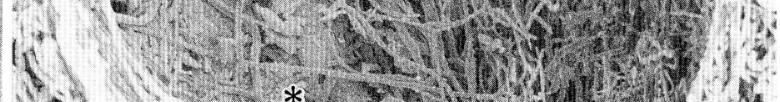
A. $\frac{*}{2}$ ant

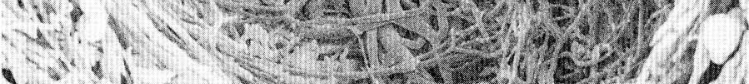

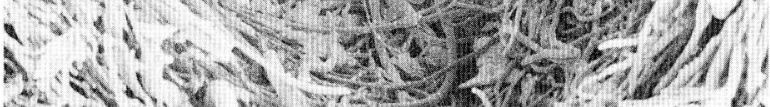
in

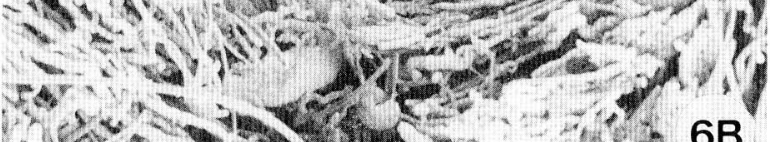
6A 


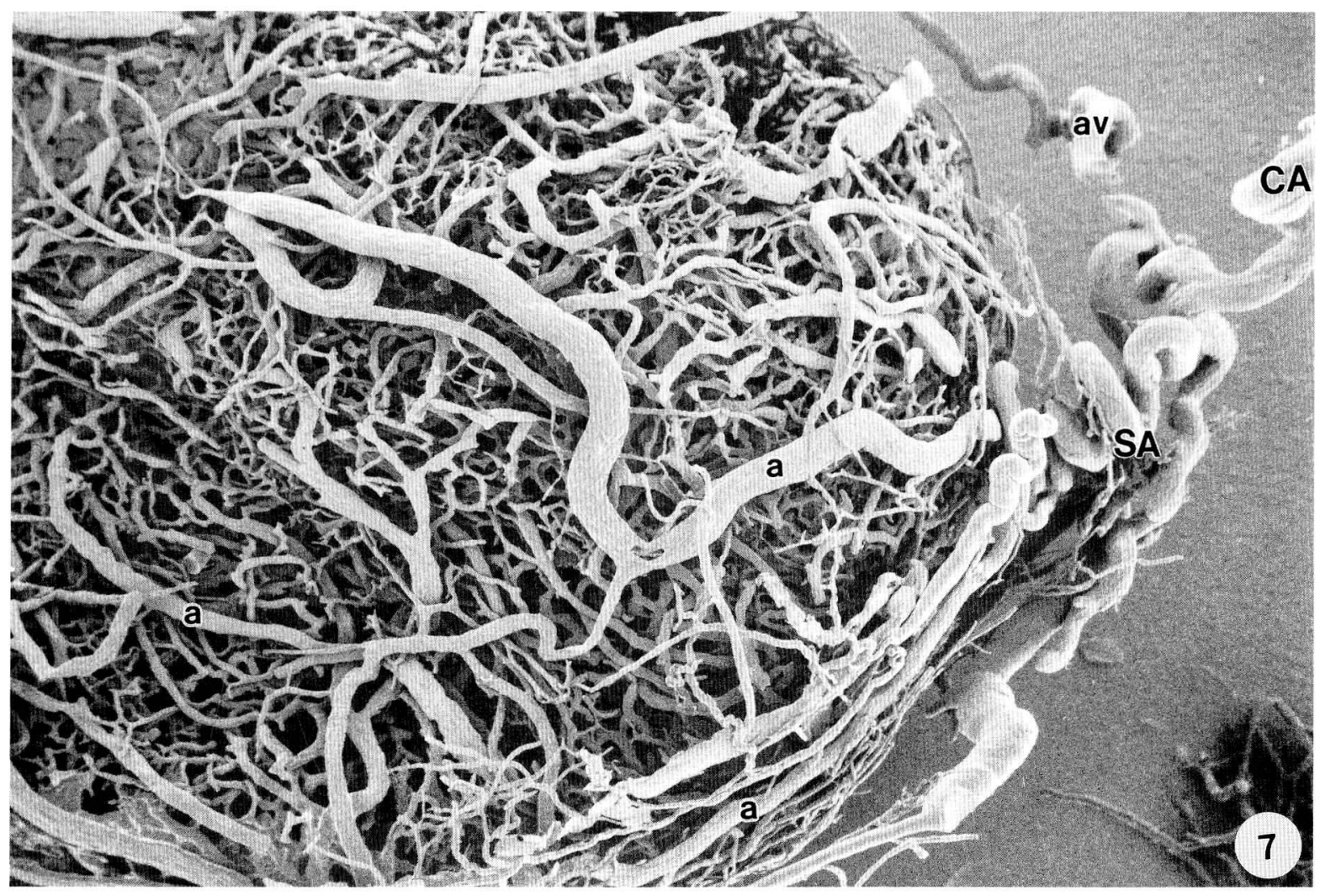

Fig. 7. Microdissected vascular cast of an inner vascular plexus, without the outer capillary plexus of an antral follicle. A spiral afferent arteriole (SA) branching from the cortical arteriole (CA) extends a few arteriole (a) that merge with inner sinusoidal capillaries. The cortical arteriole $(C A)$ is divided into the afferent vessels (av) that merge with the outer capillary plexus and stromal capillary plexus. $\times 60$

plexus is arranged as a single-layered capillary plexus, and it appears among the small secondary follicles. The plexus develops into a multilayered vascular plexus during follicular development. The plexus develops into a multilayered vascular plexus during follicular development. The plexus has one or two afferent vessels and is composed of three layers of vessels: 1) an outer layer, which consists of a thin, coarse capillary plexus; 2) an intermediate layer, which contains intermingled thick arterioles and venules; and 3) an inner layer, which has a dense, sinusoidal capillary plexus (KARDON and KESSEL, 1979; KANZAKI et al., 1982; KIKUTA et al., 1991; MaCchiarelli et al., 1992, 1993). The microvasculature of the mature follicles in the hamster, rat and rabbit is situated in the thecal layer. In the sow, the small follicles have no special vascular plexus. Soon after formation of the follicular antrum, the follicle acquires a monolayered capillary plexus. During follicular development, the plexus divides, together with several small afferent vessels, into two vascular plexuses. The inner plexus consists of single layer of sinusoidal capillaries, while the outer plexus consists of a few arterioles and venules. The inner plexus corresponds to the theca interna and the outer one to the theca externa (ANDERSEN, 1926). The microvasculature of ovarian follicles in the hamster, rat, rabbit and sow is limited to a single microcirculatory route with one or two afferent vessels, irrespective of whether there is a single, two or multi-layered vascular plexus (ANDERSEN, 1926; KARDON and KESSEL, 1979; KANZAKI et al., 1982; KIKUTA et al., 1991; FORSMAN and MCCORMACK, 1992; MACCHIARELli et al., 1992, 1993).

In the present study, a clearly defined vascular plexus, which was still not independent, appeared when secondary bovine follicles were $200-400 \mu \mathrm{m}$ in diameter. At this stage of follicular development, the layer of the theca interna started to differentiate in the bovine ovaries (data not shown).

During follicular development, the microvasculature architecture of antral follicles was arranged as two independent vascular plexuses. This architecture might be characteristic of the antral follicles of the bovine ovaries. Histologically, the structure of the 


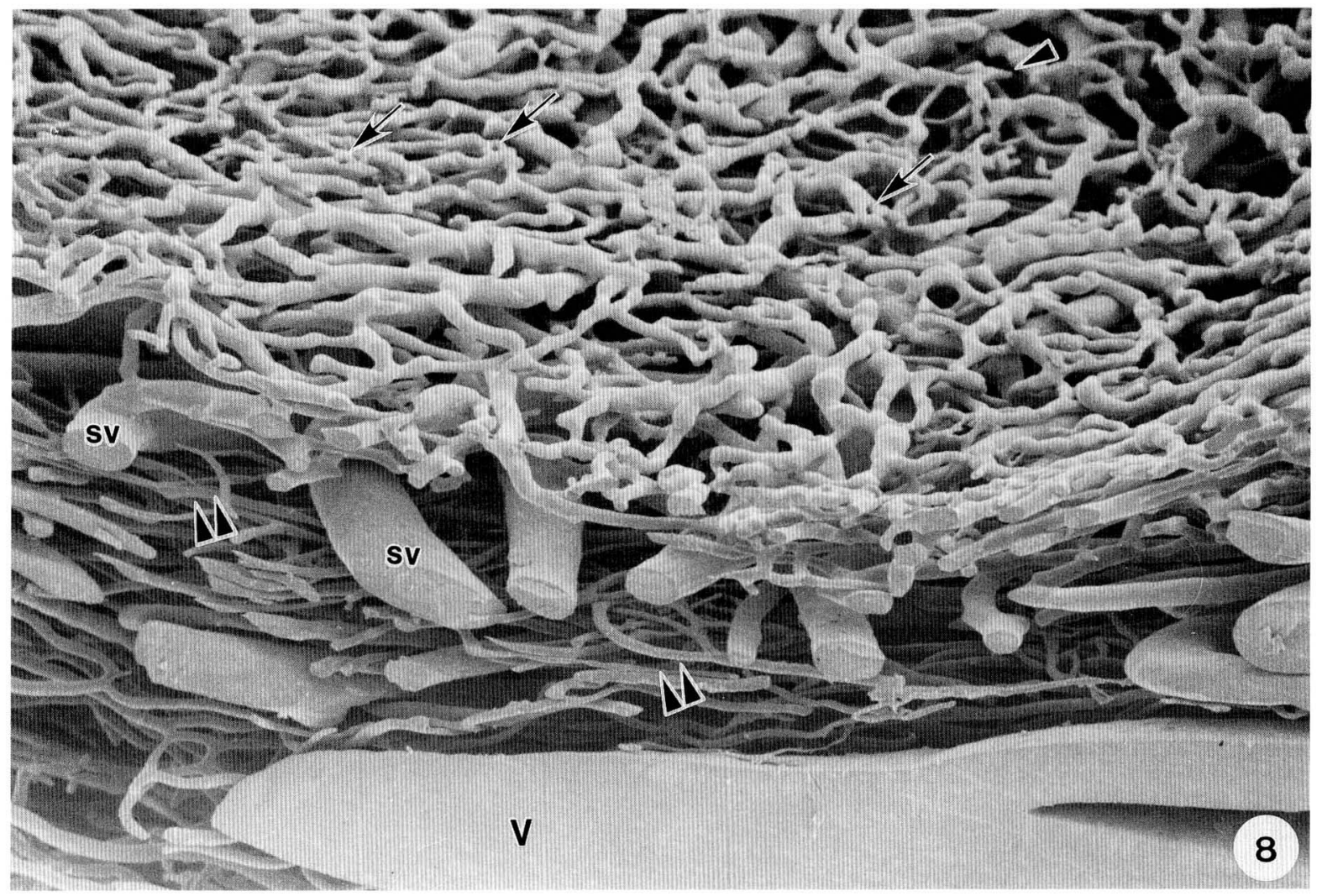

Fig. 8. View of the inner vascular plexus and the outer capillary plexus of an antral follicle. Numerous sinusoidal capillaries of the inner plexus form a dense meshwork with some evidence of angiogenesis (arrowhead) and intussusceptive microvascular growth (arrows). The outer capillaries (double arrowheads) form a rough meshwork. sv Small venule, $V$ venule. $\times 150$

outer layer in bovine follicles differed from that in rat follicles.

The inner plexus, situated in the theca interna, presumably functions as an independent microcirculatory unit (MARION et al., 1968). The cells of the theca interna differentiate under the influence of gonadotrophin (HIURA and FuJITA, 1977; HAFEZ, 1987) and they secrete estrogens in response to the luteinizing hormone (PriedKalNs et al., 1968; HAFEZ, 1987). The spiral arteriole that supplies the inner unit is involved in hormonal secretion (REYNOLDS, 1950; TAKADA et al., 1987). The increase in the numbers of blood vessels during perifollicular vascularization might result in the preferential delivery of gonadotrophin and, accordingly, in the selection and maintenance of the dominant follicle (FREDERIK et al., 1984). The follicular microvasculature begins to develop during the angiogenetic and intussusceptive microvascular growth that accompanies follicular development (Murakami et al., 1988; Paten et al., 1992). In addition, the inner unit plays an important role in the release of cumulus oocytes and the vascularization of the corpus luteum after ovulation (KÖNIG et al., 1989; YAMADA et al., 1994). The inner unit, which appears in secondary follicles, develops to provide the microvascular growth that accompanies the differentiation and secretion of the theca interna. It is suggested that the appearance and formation of the inner unit might be required for the secretion of hormones, ovulation and vascularization of the corpus luteum.

The outer plexus, which anastomoses with several stromal capillaries, is located in the theca externa (MARIon et al., 1968). The theca externa contains abundant collagen fibers within loose, areolar connective tissue and, hence, as the follicles increase rapidly in size during development, its cells are spread apart (Priedkalns and Weber, 1968; Priedkalns et al., 1968). In addition, the theca externa develops into a supporting layer for ovulation (PRIEDKALNS et al., 1968). Therefore, the outer unit, which is located as the layer that supports the inner unit, is formed from the stromal capillary network as a consequence of the rapid enlargement of developing antral follicles. 


\section{REFERENCES}

Andersen, D. H.: Lymphatics and blood vessels of the ovary of the sow. Contrib. Embryol. Carnegie Inst. 17: 107-123 (1926).

Forsman, A. D. and J. T. McCormack: Microcorrosion casts of hamster luteal and follicular vasculature throughout the estrous cycle. Anat. Rec. 233: 515-520 (1992).

Frederik, J. T., T. Shimanuki and G. S. DiZerega: Initiation of angiogenesis by human follicular fluid. Science 224: 389-390 (1984).

Hafez, E. S. E.: Folliculogenesis, egg maturation and ovulation. In: (ed. by) E. S. E. HAFEz: Reproduction in farm animals. 5th. ed. Lea \& Febiger, Philadelphia, 1987 (p. 130-167)

Hiura, M. and H. Fujita: Electron microscopy of the cytodifferentiation of the theca cell in the mouse ovary. Arch. Histol. Jap. 40: 95-105 (1977).

Kanzaki, H., H. OKamura, Y. OKuda, A. TakenaKa, K. Morimoto and T. Nishimura: Scanning electron microscopic study of rabbit ovarian follicle microvasculature using resin injection-corrosion casts. J. Anat. 134: 697-704 (1982).

KARDON, R. H. and R. G. KesSEL: SEM studies on vascular casts of the rat ovary. Scanning Electron Microsc. 3: 743-750 (1979).

Kikuta, A., G. Macchiarelli and T. Murakami: Microvasculature of ovary. In: (ed. by) G. FAMILIAR, S. MAKABE and P. M. MoTTA: Ultrastructure of the ovary. Kluwer Academic Publishers, Boston-Dordrecht, 1991 (p. 239-254).

König, H. E., W. Amselgruber and I. Rüsse: La microcirculation dans les follicles et les corps jaunes d'ovaires de bovins. Une étude anatomique par corrosion. Contracept. Fertil. Sex. 17: 179-186 (1989).

LAMOND, D. R. and M. Drost : Blood supply to the bovine ovary. J. Anim. Sci. 38: 106-112 (1974)

Macchiarelli, G., E. Vizza, S. A. NotTola, G. Familiari and P. M. MotTA: Cellular and microvascular changes of the ovarian follicle during folliculogenesis: a scanning electron microscopic study. Arch. Histol. Cytol. 55, Suppl.: 191-204 (1992)

Macchiarelli, G., S. A. Nottola, E. Vizza, G. Familiari, A. Kikuta, T. Murakami and P. M. Motta: Microvasculature of growing and atretic follicles in the rabbit ovary. A SEM study of corrosion casts. Arch. Histol. Cytol. 56: 1-12 (1993).
Marion, G. B., H. T. Gier and J. B. Choudary: Micromorphology of the bovine ovarian follicular system. J. Anim. Sci. 27: 451-465 (1968).

Murakami, T., Y. IKebuchi, A. Ohtsuka, A. Kikuta, T. TAGUCHI and 0. OHTANi: The blood vascular wreath of rat ovarian follicle, with special reference to its changes in ovulation and luteinization: a scanning electron microscopic study of corrosion casts. Arch. Histol. Cytol. 51: 299-313 (1988).

Paten, S., M. J. Alvarez, J. C. Schittny and P. H. BURRI: Intussusceptive microvascular growth: a common alternative to capillary sprouting. Arch. Histol. Cytol. 55, Suppl.: 65-75 (1992).

Priedkalns, J. and A. F. Weber: Ultrastructural studies of the bovine Graafian follicle and corpus luteum. $Z$. Zellforsch. 91: 554-573 (1968).

Priedkalns, J., A. F. Weber and R. ZemJanis: Qualitative and quantitative morphological studies of the cells of the membrane granulosa, theca interna and corpus luteum of the bovine ovary. Z. Zellforsch. 85: 501-520 (1968).

REUBer, H. W. and M. A. EMmerson : Arteriography of the internal genitalia of the cow. J. Amer. Vet. Med. Assoc. 134: 101-109 (1959).

REYNolds, S. R. M.: The vasculature of the ovary and ovarian function. Recent. Progr. Hormone Res. 5: 317344 (1950).

Takada, S., T. Shimoda, M. Nakamura, H. Mori and T. KIGAWA: Vascular pattern of mammalian ovary with special reference to the three-dimensional architecture of the spiral artery. Arch. Histol. Cytol. 50: 407-418 (1987).

Yamada, O., M. Abe, K. Takehana, K. Iwasa, T. Hiraga and T. Hiratsuka: Microvasculature of mature bovine follicles and its changes with ovulation. J. Reprod. Devel. 40: 307-315 (1994).

Prof. Mitsuo ABE

Department of Veterinary Anatomy Rakuno Gakuen University

Ebetsu, 069 Japan

阿部 光 雄

069 北海道江別市文京台緑町 582

酪農学園大学

獣医解剖学教室 